\title{
EVALUATION EFFECT OF POLARITY OF THE COMPOUND FROM Sonchus arvensis (Linn.) LEAVES AS HYPERTENSION INHIBITOR
}

\author{
Suryani $^{1,3^{*}}$, E. Y. Sukandar ${ }^{1}$, M. Insanu ${ }^{2}$, and N. F. Kurniati ${ }^{1}$ \\ ${ }^{1}$ Department of Pharmacology-Clinical Pharmacy, School of Pharmacy, Institut Teknologi \\ Bandung, Bandung 40132, Indonesia. \\ ${ }^{2}$ Department of Pharmaceutical Biology, School of Pharmacy, Institut Teknologi Bandung, \\ Bandung 40132, Indonesia. \\ ${ }^{3}$ Department of Pharmacology and Toxicology, Faculty of Pharmacy, University of Jenderal \\ Achmad Yani, Cimahi 40533, Indonesia \\ *E-mail: suryaniyaniapt@gmail.com
}

\begin{abstract}
Sonchus arvensis (Linn) was empirically used for the treatment of hypertension. The extract has a good effect on reducing blood pressure. The compound in S. arvensis, a role in controlling the blood pressure still unknown. This experiment evaluated the antihypertension activity of the compound from $S$. arvensis dependent on the polarity of the compound. Evaluation of blood pressure was carried out using rats with a tail-cuff method, and the mechanism evaluated using the frog's heart by observing changes in cardiac contraction. Epinephrine was used as acute inducer hypertension. The result showed that polar and nonpolar compounds did not show antihypertension activity, it was characterized by high of the systolic and diastolic blood pressure, and the semi-polar fraction contains semi-polar compounds were able to inhibit epinephrine-induced hypertension. The result showed that the dose of $16 \mathrm{mg} / \mathrm{kg}$ could prevent as much as $68.24 \%$ and $58.56 \%$ of the elevating systolic and diastolic blood pressure. This Result equivalent to atenolol $4.5 \mathrm{mg} / \mathrm{kg}$ as a beta-receptors antagonist. The effect was correlated to the lowered impact on heart rate in the ex vivo method. The suggested potential mechanism is blocking the beta-receptor in cardiomyocyte, and blood pressure can be decreased because of reducing cardiac output and heart contraction. Semi-polar fraction collected by ethyl acetate as solvent. That fraction was rich in flavonoid and phenol compounds than other fractions. One of the compounds that characterized in the semi-polar fraction is luteolin. It is the potential candidate who has acted as antihypertension.
\end{abstract}

Keywords: Hypertension, S. arvensis, Flavonoids, Luteolin, Polarity

(C) RASĀYAN. All rights reserved

\section{INTRODUCTION}

Hypertension is one of the conditions that significantly increase the risk of stroke, kidney failure, and heart failure. Nowadays, it was significantly caused the premature death. The leading causes of increased blood pressure are high consumption of unhealthy food, lack of physical activity, alcohol consumption, and smoking. World Health Organization (WHO) showed that 1.13 billion people worldwide have hypertension. ${ }^{1}$ WHO has a target to reduce the hypertension population by $25 \%$ in $2025 .{ }^{2}$ Prevention of hypertension is one of the major processes to reduce the population of hypertension. Developing traditional medicine becomes one of the choices for treating or inhibiting hypertension because it can be a supplement to control blood pressure.

Indonesia is one of the countries with very high biodiversity. Thus, the government encourages researchers to develop traditional medicine or supplements from Indonesian. One of the purposes is helping and to reducing the hypertension population. Because of that reaches as much as $34.1 \%$ in 2018. It is higher than the prevalence in 2013., In this study has a focus to develop the potential of Soncus arvensis as one of the plants from Indonesia, which has empirically used to control the blood pressure.

Sonchus arvensis (Linn.), perennial sow-thistle is the Asteraceae family and known as tempuyung in Indonesia, is one of the very easily found plants in Indonesia, India, and China. ${ }^{5-7}$ It has characteristics of

Rasayan J. Chem., 13(3), 1807-1816(2020)

http://dx.doi.org/10.31788/ RJC.2020.1335843

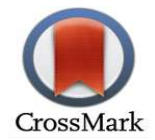


RASĀYAN J. Chem.

Vol. 13 | No. 3 |1807-1816| July - September | 2020

weeds with stolone which stretch above the ground and are covered by buds, with green leaves and yellow flowers. It is a herbaceous plant that has a very high flavonoid content which has been identified as containing orientin, hyperoside, quercetin, catechin, rutin, myricetin, and kaempferol. ${ }^{8}$ The high flavonoid content may be one reason why leaves tempuyung has many pharmacological activities. However, to ascertain whether the flavonoids have an essential role in the resulting activity should be conducted indepth research.

Scientifically, S. arvensis has been proven that have pharmacological effects. That was a diuretic, antiinflammatory, immunomodulatory, hepatoprotective, hypoglycemic effect, anticalculi, and xanthine oxidase inhibitor. ${ }^{5,9-12}$ The results of acute and subchronic toxicity tests on ethyl acetate extract disclosed no toxic effects and death in a single high-dose administration and repeated administration for 90 days ${ }^{13}$. S. arvensis showing a high diuretic, anti-inflammatory, and antioxidant effect, it possibly has an impact on blood pressure, where one of the causes of increased blood pressure is inflammation in blood vessel endothelial cells due to high contents of ROS (reactive oxygen species), as well as increased contraction of blood vessels and the heart. Another result showed a dose combination $S$. arvensis, and Andredera cordivolia (Ten.) v. Steenis was inhibit angiotensin II in vivo method and S. arvensis showed activity to inhibit the angiotensin converting enzyme activity in in vitro method. ${ }^{14-15}$

$S$. arvensis has potential as an antihypertensive agent with a variety of mechanisms of action, including diuretics, ACE inhibitors, and angiotensin receptor blockers but requires further study to confirm this. Previous studies have not been able to determine whether the content of $S$. arvensis which has activity on blood pressure so that in this study an activity evaluation will be carried out in the leaves as an initial step in determining compounds that have antihypertensive activity. This experiment was evaluated the antihypertensive effects based on the compound polarity in $S$. arvensis leaves, this study aimed to detect the main compound that has an activity to regulate the blood pressure and predicting the occurring working mechanism in the heart.

\section{Plant Material}

\section{EXPERIMENTAL}

S. arvensis obtained from Kimia Farma Corp. Herbal plantations, Bandung, West Java, Indonesia. The plants had been identified at Herbarium Bandungense, School of Life Science and Technology, Institut Teknologi Bandung, Indonesia.

\section{Extraction Preparation}

The plants were selected, dried, and mashed by Kimia Farma, Corp. The extraction method was maceration at room temperature, and the solvent was ethanol $96 \%$ (1:8, plant: solvent). The compounds in the extracts that have been dried were separated based on the compound polarity using n-hexane, ethyl acetate, and water (1:1) as a solvent and the method was liquid-liquid extraction. The sample was concentrated with a rotary evaporator and dried in an oven at $50^{\circ} \mathrm{C} .^{16}$

For the pharmacological effect test, the sample was dissolved in carboxymethyl cellulose-Na (CMC-Na) $5 \%$ solution for oral administration, dimethyl sulfoxide (DMSO) $1 \%$ and deionized water.

\section{Total Phenolic Content}

Total phenolic content in the compound was determined by Folin-Ciocalteu Colorimetric method with gallic acid as a standard. Gallic acid solution was made with a concentration of $50-150 \mu \mathrm{g} / \mathrm{mL}$, while the test sample made with a concentration of $2000 \mu \mathrm{g} / \mathrm{mL}$ in methanol (Merck, Corp.). The Folin-Ciocalteu reagent solution diluted with aqua dest at 1:10. The sample volume of $0.5 \mathrm{ml}$ was added $5 \mathrm{ml}$ of the reagent and $4 \mathrm{ml}$ of $\mathrm{Na}_{2} \mathrm{CO}_{3}$ (Merck, Corp.) $1 \mathrm{M}$ and incubated for 15 minutes at room temperature. The changes in color reactions that occurred were measured using a UV-VIS spectrophotometer at a wavelength of 739 $\mathrm{nm}$. The determination of the total phenol content in the test sample was calculated based on the equivalence of the amount of gallic acid per gram of the test sample (mg GA/g). ${ }^{17}$

\section{Total Flavonoid Content}

Total flavonoid content in the compound was determined by the colourimetric method. Quercetin solution as a standard made in methanol with a concentration of $20-100 \mu \mathrm{g} / \mathrm{mL}$ and the test compound was made 
RASĀYAN J. Chem.

Vol. 13 | No. 3 |1807-1816| July - September | 2020

with a concentration of $1000 \mu \mathrm{g} / \mathrm{mL}$. 0.5 sample was added $1.5 \mathrm{ml}$ of methanol (Merck, Corp.), $0.1 \mathrm{ml}$ of $\mathrm{AlCl}_{3} 10 \%, 0.1 \mathrm{ml}$ of sodium acetate $1 \mathrm{M}$, and $2.8 \mathrm{ml}$ of distilled water. The solution incubated for 30 minutes at room temperature and absorbance was measured using a UV-VIS spectrophotometer at a wavelength of $435.5 \mathrm{~nm}$. Total flavonoid content was shown in equivalence to $\mathrm{mg}$ quercetin/gram sample $(\mathrm{mg} \mathrm{Q} / \mathrm{g}){ }^{18-19}$

\section{Identification of Marker}

Identification of marker compounds in $S$. arvensis was carried out using a thin-layer chromatography method using the stationary phase was Silica Gel GF 254 (Merck Corp.), and the mobile phase was toluene: ethyl acetate: formic acid= 6:4:0,1. The spot appearance was citroborat. The standard compound used was Luteolin (Sigma Aldrich, Corp.).

\section{Densitometry Analysis}

Marker compound assay in S. arvensis was performed using densitometry method. Luteolin standard curve was made with a concentration range $(0,1-2 \mathrm{mg} / \mathrm{mL})$ on the plate of Silica Gel GF 254, and the mobile phase was toluene: ethyl acetate: formic acid $=6: 4: 0,1$.

The process of staining the sample on the TLC plate was done automatically and detected using a densitometer at a wavelength of $365 \mathrm{~nm}$. The calculation of contents was based on the results of the sample density area on the standard linear regression equation and expressed in the $\mathrm{mgLut} / \mathrm{g}$ sample.

\section{Evaluation of Blood Pressure}

Male Wistar rat aged 10-12 weeks with weights of 200-250 grams were used, purchased from Animal Laboratory, Inter-University Research Center, Institut Teknologi Bandung. The rats were acclimatized for two weeks with temperatures of $22-25^{\circ} \mathrm{C}$, cycles of 12 hours dark/light, food and drinks ad libitum.

The Research Ethics Committee of Padjadjaran University, Bandung approved the research protocol, for animal subjects in research with number 667/UN6.KEP/EC/2018.

After the protocol had been approved, the experiment began with animal habituation on the blood pressure measuring device (a tail-cuff method, CODA noninvasive Blood Pressure system, Kent Scientific Corporation) and was continued with measurement of the initial blood pressure. Only the animals that had blood pressure below $120 / 70 \mathrm{mmHg}$ would be used in the study.

Evaluation of the antihypertension effect was used epinephrine dose of $0.25 \mathrm{mg} / \mathrm{kg}$ as hypertension inductor. The compound test dose was based on the yield produced in the extraction process. The test animals were grouped into seven test groups $(\mathrm{n}=5)$. Each test animal was measured at baseline (T0), and given the test compound per orally, the positive control group was given CMC-Na $0.5 \%$ and atenolol 4.5 $\mathrm{mg} / \mathrm{kg}$ as a reference drug. Epinephrine was given intraperitoneal at 30 minutes after the sample administration. At the minute 60 (T60), the final blood pressure measurements were taken with the systolic blood pressure, diastolic, and mean as the measurement parameters.

\section{Identified the Mechanism of Action Using the Frog's Heart.}

This research used a 50-75gram male frog heart (Duttaphrynus melanostictus) from Pharmacology Laboratory, University of Jenderal Achmad Yani, Cimahi, Indonesia. The animals had been identified at Padjajaran University, Indonesia. The testing was divided into 7 test groups $(\mathrm{n}=5)$.

The frog was anaesthetized using ketamine at a dose of $100 \mathrm{mg} / \mathrm{kg}$. Then, they were put on the fixation board and cut in the part of the pericardium that wrapped the heart with an inverted Y slice, and the heart was removed, then the frenulum cordis was hooked using a hook connected to kymograph. The heart contraction was recorded for 90 seconds with a rotation speed of $2.5 \mathrm{~mm} / \mathrm{s}$ with the test parameters in the form of frequency and amplitude of the heartbeat. Krebs's solution was used to keep the heart alive. Norepinephrine $2.9 \times 10^{-3} \mathrm{mM}$ was the contraction inductor. The recording of the heart contraction was performed in each frog in the normal state and continued with the administration of epinephrine by droplets. It is together with the test compound directly to the heart. Observations were made about changes in the frequency and amplitude of the heart contraction, which would be analyzed as heart rate and echocardiogram pattern. Bisoprolol was used as comparative medicine (negative control). ${ }^{20}$ 
RASĀYAN J. Chem.

Vol. 13 | No. 3 |1807-1816| July - September | 2020

\section{Statistical Analysis}

The data were illustrated in mean \pm deviation (SD) and analyzed using the GraphPad Prism Software with a one-way ANOVA statistical test with significance $\mathrm{p}<0.05$.

\section{RESULTS AND DISCUSSION}

\section{Phytochemical Compounds, Concentration of Phenol and Flavonoids Content on the} Sonchus arvensis Leaves Fraction

Dried S. arvensis leaves extracted using ethanol $96 \%$. The yield of the extract is $7.67 \% \mathrm{~g} / \mathrm{g}$. Furthermore, the extract was liquid-liquid extracted to produce three types of parts. They were hexane fraction $(42.66 \% \pm 1.9 \%)$ as nonpolar fractions, water fraction $(29,05 \pm 0.4 \%)$ as polar fractions, and ethyl acetate fraction $(8.69 \pm 0.21 \%)$ as a semi-polar fraction. The contents of phytochemical compounds contained in each fraction were in Table-1. It disclosed that the separation process has succeeded in separating compounds based on the polarity. ${ }^{21,22}$ Each fraction did not contain similar secondary metabolites.

Table 1. Phytochemical Content of Three Fractions of Sonchus arvensis (Linn.) Leaves.

\begin{tabular}{cl|c|c|c}
\hline \multirow{2}{*}{ Phytochemical } & \multicolumn{3}{|c}{ Results } \\
\cline { 2 - 4 } & Polar fraction & Semi polar fraction & Nonpolar fraction \\
\hline$\bullet$ & Flavonoids & + & + & - \\
\hline$\bullet$ & Saponin & + & - & - \\
\hline$\bullet$ & Quinones & + & + & - \\
\hline$\bullet$ & Tannins & + & + & - \\
\hline$\bullet$ & Polyphenols & + & + & - \\
\hline$\bullet$ & Alkaloids & - & - & + \\
\hline$\bullet$ & Steroid and Triterpenoid & - & + & + \\
\hline$\bullet$ & Mono and Sesquiterpene & - & + & + \\
\hline
\end{tabular}

Data presented as a result of colourimetric and sedimentation. $n=3$

S. arvensis has been known to have abundant total flavonoid and phenol contents. ${ }^{8}$ Table-2 showed that a semi-polar fraction had a higher concentration of phenol and flavonoid contents than a polar fraction, while the phenol and flavonoid contents in hexane fraction not detected up to $5000 \mu \mathrm{g} / \mathrm{mL}$.

Table-2: Concentration of Phenol and Flavonoid Concentrations of the Fractions of S. arvensis (Linn.).

\begin{tabular}{c|c|c}
\hline Sample & Phenol Total $(\mathrm{mgGA} / \mathrm{g})$ & Flavonoids Total $(\mathrm{mgQ} / \mathrm{g})$ \\
\hline Polar fraction & $6.77 \pm 1.80$ & $5.21 \pm 0.79$ \\
\hline Semi polar fraction & $20.83 \pm 2.20$ & $84.69 \pm 1.65$ \\
\hline Nonpolar fraction & 0 & 0
\end{tabular}

Data showed the mean \pm standard deviation. $n=3$

The Effect of the Polarity Compound of the Sonchus arvensis Leaves on Blood Pressure

The principle of this study was a preventive method. Each fraction was given orally before epinephrine injection. The results showed that the administration of epinephrine of $0.25 \mathrm{mg} / \mathrm{kg}$ to the positive control was able to induce high blood pressure. It could increase the diastolic blood pressure (DBP) $38.29 \pm 6.67 \%$, systolic blood pressure (SBP) $28.22 \pm 2.47 \%$, and mean blood pressure (MBP) $30.43 \pm 9.00 \%$ (Fig.-1.) significantly towards normal blood pressure $(\mathrm{p}<0,05)$. The dose of epinephrine $0.25 \mathrm{mg} / \mathrm{kg}$ could induce acute hypertension. Atenolol as the reference group showed significantly inhibit hypertension (Fig 1.). Furthermore, semi-polar fraction administration at doses of 8 and $16 \mathrm{mg} / \mathrm{kg}$ was able to attenuate the increase of blood pressure induced by epinephrine. It was marked by an increase in blood pressure in the semi-polar fraction group at $8 \mathrm{mg} / \mathrm{kg}$ at $20.63 \pm 5.51 \%$ for DMB, $24.10 \pm 6.00 \%$ for SBP, and $22.67 \pm 5.185 \%$ for (MBP) and the dose $16 \mathrm{mg} / \mathrm{kg}$ showed a higher activity to control the blood pressure which is only increased $12.28 \pm 5.66 \%$ for DBP, $11.44 \pm 3.27 \%$ for SBP, and $11.19 \pm 5.69 \%$ for MBP. In Figure-1(a-c), epinephrine could induce hypertension for 60 minutes indicated by elevated diastolic and systolic blood pressure on male Wistar rats $\left(\mathrm{Key}:{ }^{*}=\mathrm{p}<0.05\right)$ compared to the normal group. Some fraction effects of 
RASĀYAN J. Chem.

Vol. 13 | No. 3 |1807-1816| July - September | 2020

inhibiting high blood pressure. It shows (d-f) semi-polar fraction has lowest on the increase of blood pressure after induction with significant effect compared to negative control group (Key: $\#=p<0.001)$ and $16 \mathrm{mg} / \mathrm{kg}$ of dose of semi-polar fraction has similar effect to standard (atenolol groups) (Key: ** $=\mathrm{p}>0.05$ ). $\mathrm{n}=5$.
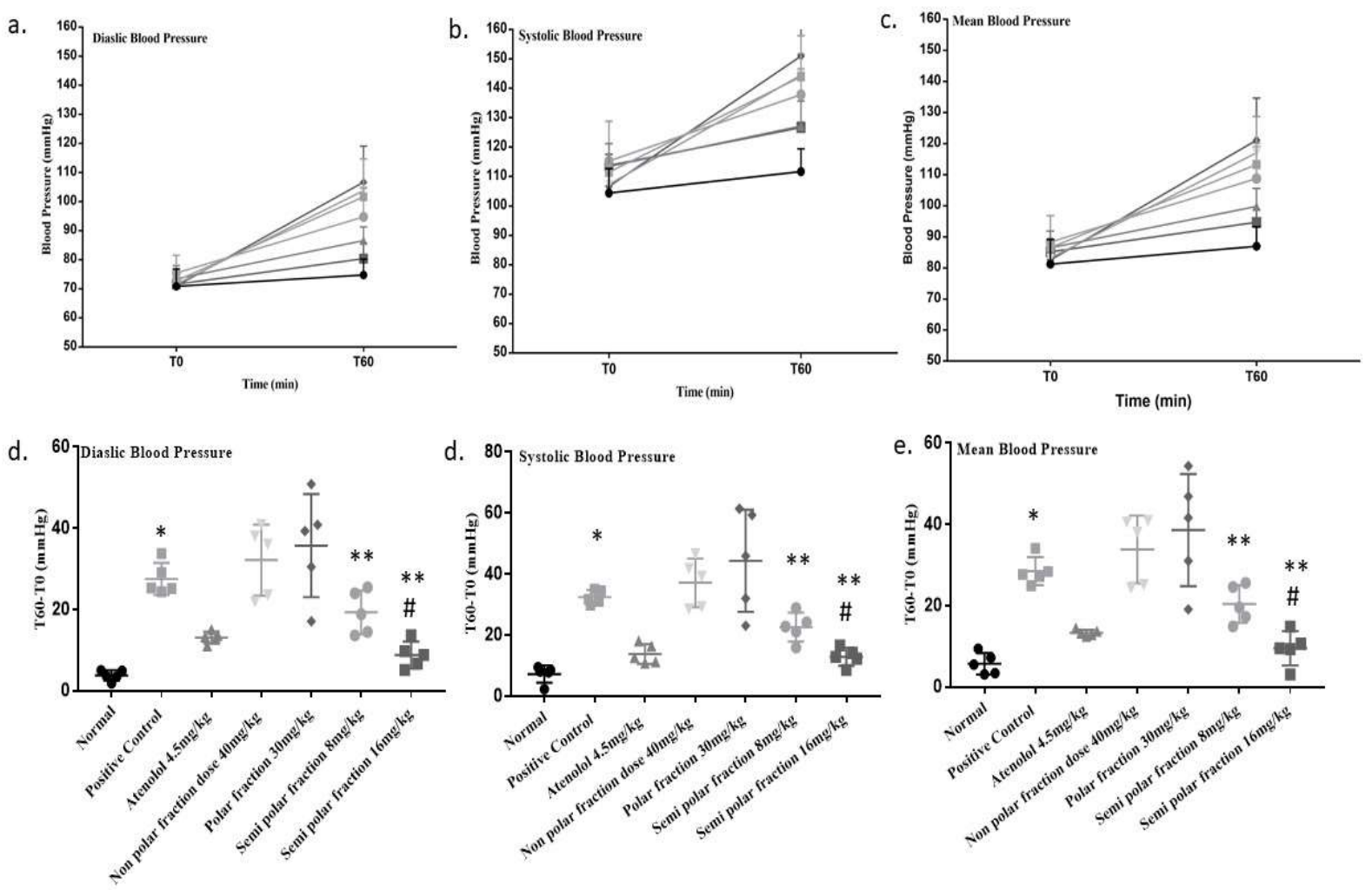

Fig.-1: Effect of Nonpolar, Polar and Semi-polar Compounds of the Fraction of S. arvensis (Linn.) to inhibit Hypertension induced by Epinephrine.

On the other hand, the polar fraction showed that the increase in blood pressure was significantly exceeded the positive control group (DBP 47.86 $\pm 19.55 \%$, SBP $37.01 \pm 14.79 \%$, and MBP $43.36 \pm 17.45 \%$ ). Moreover, the nonpolar fraction disclosed results equivalent to the polar fraction in which it could not prevent an increase of blood pressure induced by epinephrine (DBP $47.18 \pm 10.97 \%$, SBP $35.78 \pm 5.90 \%$, and MBP $42.43 \pm 8.39 \%)$.

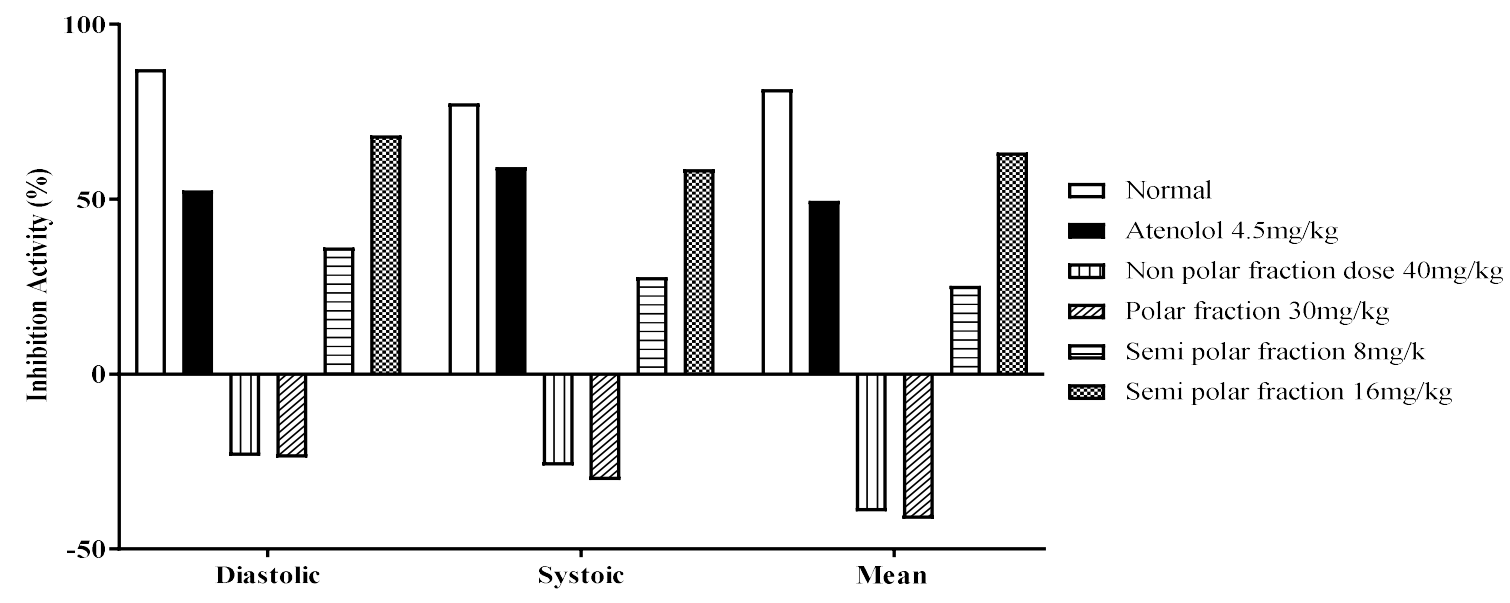

Fig.-2: Percentage of Activity in Inhibiting Hypertension 
RASĀYAN J. Chem.

Vol. 13 | No. 3 |1807-1816| July - September | 2020

It compares elevated the blood pressure to the positive control. The data calculated from the mean of each group $(\mathrm{n}=5)$. Positive value show activity to inhibit hypertension, and the negative value did not show that activity.

\section{Detection of Mechanism of Action as Antihypertension}

In determining the mechanism, the experiment was continued in the ex vivo method using the frog's heart. The heart rhythm movements have recorded and displayed in a manual electrocardiogram (ECG) (Fig.-3). The cardiac activity was indicated as the contraction of sinus venosus, it was occurred because of the electrical signal that spreads over the heart. The atrial will active after the sinus venosus, the ventricle moved after the atria, and the aortic trunk active after the ventricle. Each peak in an ECG corresponds to changes in specific regions of the heart, the $\mathrm{P}$ wave is atrial depolarization, the QRS complex is atrial repolarization and ventricular depolarization, and $\mathrm{T}$ wave is ventricular repolarization. ${ }^{23,24}$

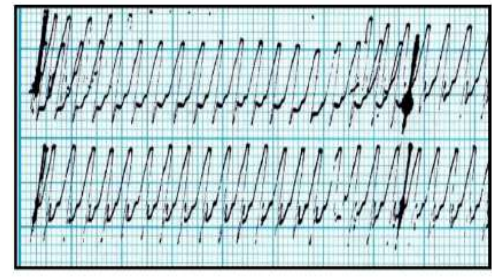

a.

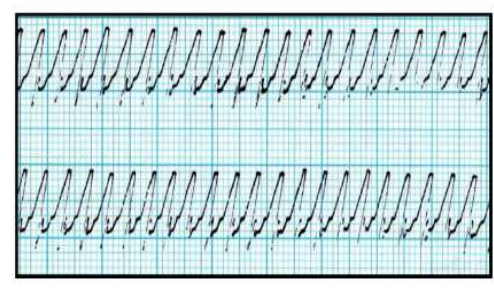

d.

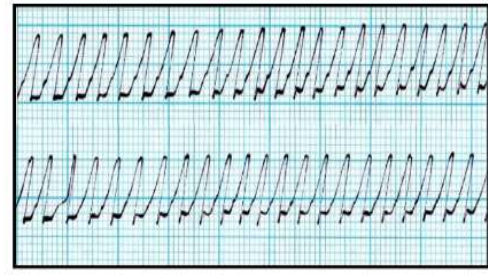

b.

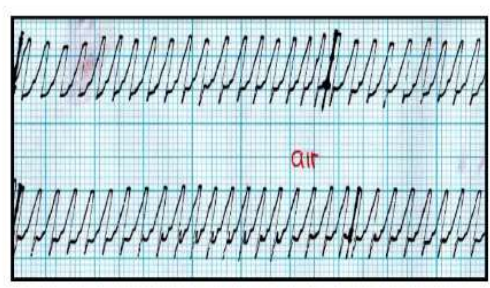

e.

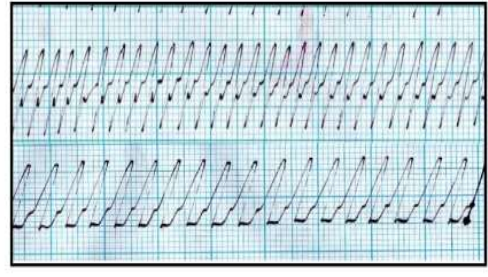

c.

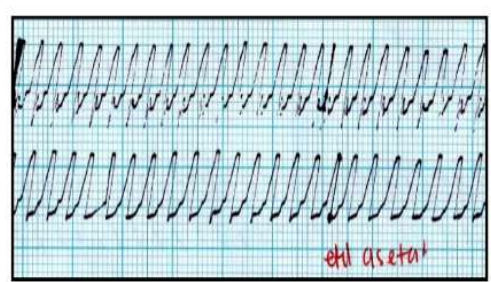

f.

Fig.-3. Frog's Heart Electrocardiogram Pattern with Defined P, QRS, and T Waves.

In Figi.-3, groups consist of norepinephrine (positive control) showed elevation of the ST segment (a), DMSO as solvent did not give significant effect to the pattern ECG compare to a positive control (b), bisoprolol showed positive $\mathrm{T}$ and decreased the peak and longer of ST-segment (c), nonpolar fraction showed positive T wave and ST-segment (d), polar fraction increase RS and ST-segment (e), and semipolar fraction negative $\mathrm{T}$ wave and decrease ST segment(f).

The parameters are heart rate and amplitude of the heart activity. In this study, norepinephrine reduced the amplitude (distance between two of the peaks in an ECG) $46.12 \pm 3.74 \%$ (Fig.-4a) and increased the heart rate (heartbeat $/ \mathrm{min}$ ) $28.31 \pm 1.46 \%$ (Fig.-4b).

\section{Marker of Sonchus arvensis Leaves}

Table-1 showed that semi-polar fraction contained phytochemical compounds in the classes of flavonoids, quinones, tannins, polyphenols, steroids, and terpenes. The concentration of phenol and flavonoid total was content on ethyl acetate fraction were $20.83 \pm 2.20 \mathrm{mg}$ equivalent to Gallic acid per gram fraction and $84.69 \pm 1.65 \mathrm{mg}$ equivalent to quercetin per gram fraction. The monitoring of the chromatogram patterns revealed that semi-polar fraction had the same rf value as luteolin which was 0.34 and was not found in the other two fractions. The result of densitometry analysis in a semi-polar fraction of $S$. arvensis contains luteolin $0.65 \pm 0.059 \mathrm{mg}$ luteolin per gram fraction. 
RASĀYAN J. Chem.

Vol. 13 | No. 3 |1807-1816| July - September | 2020

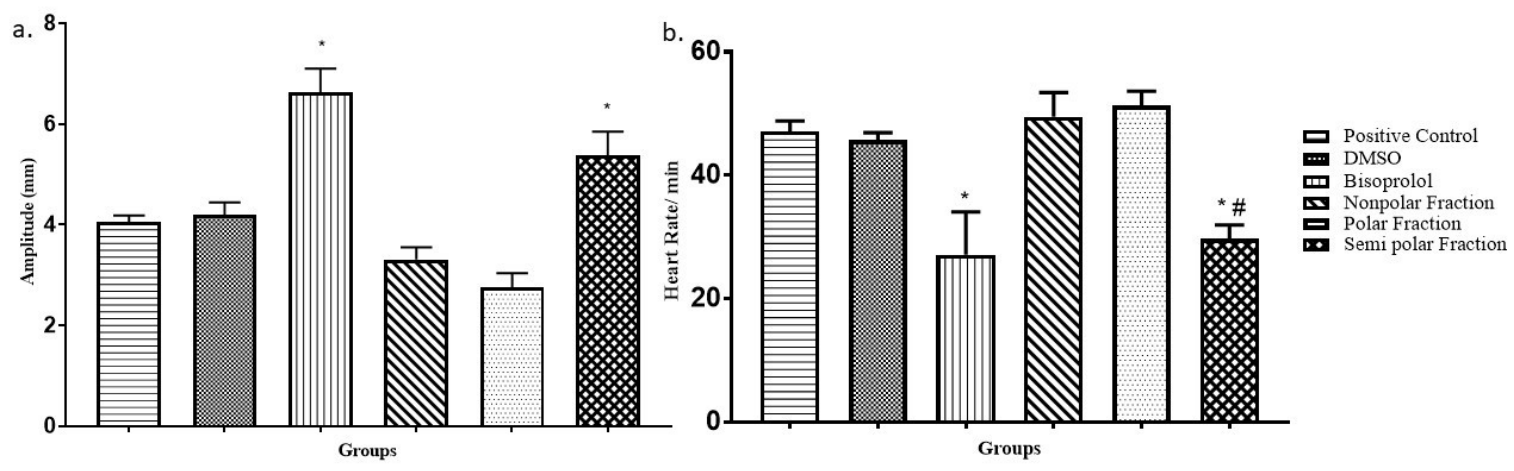

Fig.-4. Effect of Sonchus arvensis Fraction on Amplitude (a) and Heart Rate (b) of Frog's Heart induced by norepinephrine. Data are shown as mean $\pm \mathrm{SD}$. $\mathrm{N}=5$, * means $\mathrm{p}<0.05$ compared to the positive control, \# means $\mathrm{p}>0.05$ compared to bisoprolol

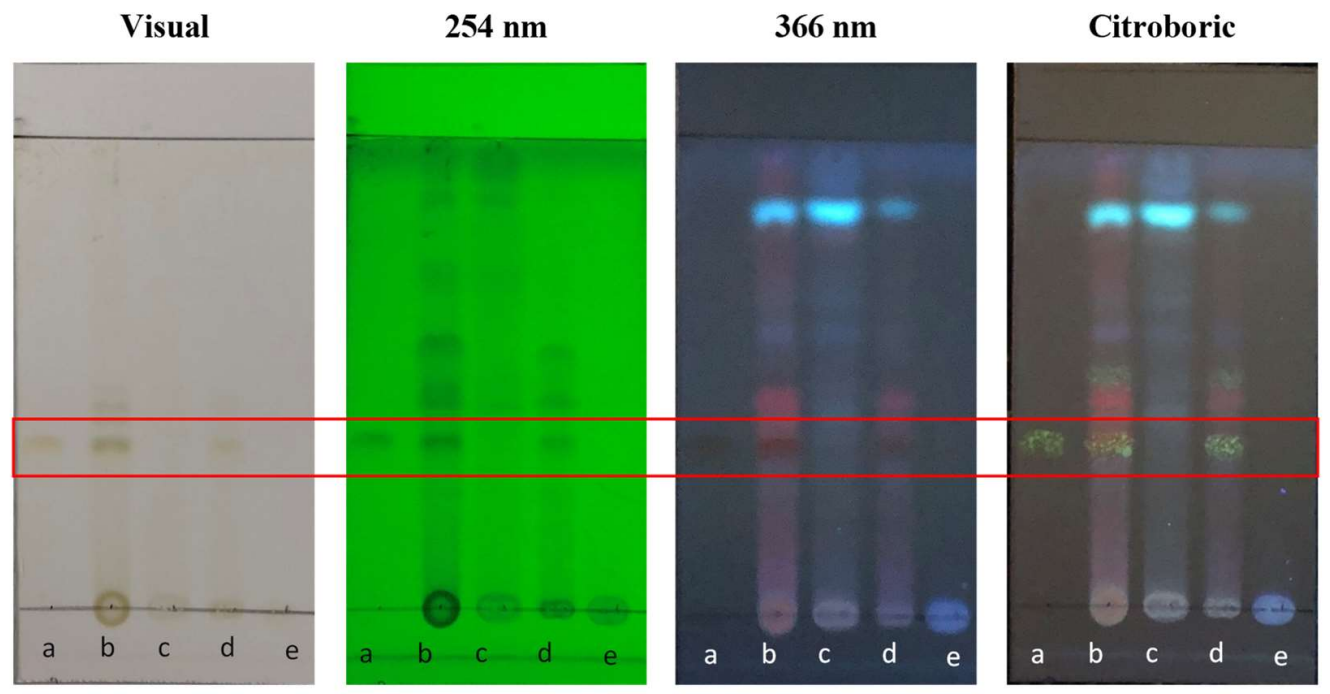

Fig.-5: Thin-layer Chromatography Plates for the Pigment of Fractions of Sonchus arvensis Leaves. (a) Luteolin as Standard, (b) Ethanol Extract, and (d) Semi-polar Fraction showed High Fluorescence after sprayed by Citroboric. It indicated that contain high Flavonoid Compound than (e) Polar Fraction and (c) Nonpolar Fraction

\section{Discussion}

In this study, epinephrine was used to induce acute hypertension in male Wistar rats by stimulating preprejunctional $\beta$-adrenergic receptors that would facilitate exocytonic norepinephrine from sympathetic nerve endings. ${ }^{21-24}$ The acute hypertension rat can make in 60 minutes after induction of epinephrine 0.25 $\mathrm{mg} / \mathrm{kg}$. It has significant $(\mathrm{p}<0.05)$ elevated the diastolic $(\mathrm{DBP})$, systolic $(\mathrm{SBP})$ and mean arterial blood pressure (MBP) of normotensive rats (Fig.-1). The mean normotensive systolic and diastolic the blood pressure of rat is $107.92 \pm 3.26 / 72.82 \pm 4.83 \mathrm{mmHg}$, and the epinephrine can increase the SBP as much as $31.18 \pm 3.01 \mathrm{mmHg}$ and the DBP as much as $27.82 \pm 4.64 \mathrm{mmHg}$ (Fig. $2 \mathrm{~d}$ and e). This method success in making the hypertension rat. The approach of this experiment is used the beta-blocker mechanism because of that atenolol was used for reference groups. Atenolol is a cardioselective beta-adrenoreceptor antagonist that is an active antihypertensive agent. ${ }^{27}$ The results showed that atenolol was sufficient to inhibit the activity of epinephrine, and it has significant to prevent the enhancement of the DBP, SDP, and MBP. The normal, positive control and atenolol groups were used to validating the method. This method was great to be one of the choices to check the activity of the new compound as an antihypertension based oh betablockers activity.

The result showed various part of the compound in the S. arvensis leaves, which has separated based on the polarity divided into the three-part of fraction has a different effect on the blood pressure. The polar and 
RASĀYAN J. Chem.

Vol. 13 | No. 3 |1807-1816| July - September | 2020

nonpolar fraction did not have an activity to prevent the activity of epinephrine on inducing hypertension because that has no difference significantly $(\mathrm{p}<0.05)$ compare to positive control groups. Another result was the polar fraction increased the blood pressure more than positive control groups. It was showed the polar compound of the $S$. arvensis has another potential to have a synergistic effect with the epinephrine. The semi-polar fraction has activity in lowering the blood pressure. It has inhibited the elevating of the diastolic, systolic, and mean blood pressure (Fig.-1). Two variety of doses of semi-polar fraction showed a great activity to inhibit hypertension. The highest dose of $16 \mathrm{mg} / \mathrm{kg}$ has a similar effect to the atenolol, and it was inhibiting the elevated blood pressure as much as $68.24 \%$ for DBP, $58.56 \%$ for SBP and $63.25 \%$ for MBP. The atenolol could inhibit hypertension as much as $52.48 \%$ for DBP, 59.10 for SBP and $49.52 \%$ for MBP. Overall, the results indicated that the candidate of compounds in S. arvensis leaves that had antihypertension effects contained on the semi-polar polar fraction, and it was possible compounds.

The activity to prevent hypertension observed with epinephrine. It is a beta-receptor agonist with potent to promote high blood pressure. ${ }^{25-27}$ Epinephrine was exposed to the heart to increase heart rate by stimulating $\beta 1$ adrenoreceptor and vasoconstriction. ${ }^{30}$ In this study showed adrenaline was increasing the contraction and relaxation, it changes the configuration of the action potential in heart muscle. In the frog heart, the adrenaline induced elevating of the slow inward. It is an effect on the prolongation of action potential and potentiation of contraction. ${ }^{32}$

The semi-polar fraction at a concentration of $0.9 \mathrm{mg} / \mathrm{ml}$ could decrease heart contraction. It shows by decrease the RS and ST-segment (Fig.-3f). The effect of this condition was changed the ventricular depolarization and ventricular repolarization, which has capable of reducing the heart rate (Fig. 4b). It is correlated to activity semi-polar fraction to inhibit hypertension on in vivo tests. The heart rate and cardiac output were suppressed in a dose-dependent manner. The highest dose has the most significant effect on depressing the high blood pressure through the beta-receptor.

Polar fraction showed an increased heart rate and reduced the distance between two R segments. It means the polar fraction contains a compound that effects to increase the atrial depolarization and repolarization and the other effect is increased ventricular depolarization and repolarization. It showed a polar compound on $S$. arvensis has potency as cardioprotective for heart failure to increase the strength of muscular contraction. $^{32}$

The pharmacology effect from traditional medicine has correlated to the compound that contains. $S$. arvensis is one of the plants that abundant in the flavonoid contain. The separated compound based on the polarity affects the pharmacology activity. Semi-polar compound on the fraction with ethyl acetate as solvent shows the best activity to the blood pressure than other fractions. The effect from that because of semi-polar fraction contains a high of total phenol and flavonoids ${ }^{8}$. The flavonoid compounds were alleged to have an essential role in the pharmacological effects produced by $S$. arvensis.

This study was identified luteolin as one of the types of flavonoids contained in S. arvensis. It was seen in the thin layer chromatography method. Luteolin was a candidate for the compound that affected the effective inhibition of epinephrine in inducing high blood pressure. Besides, luteolin was a compound that had a direct effect on NO production, which played a role in vasorelaxant, and has excellent activity as an antioxidant. $^{33-35}$

This study only determines the group of compounds that have a role in controlling blood pressure, so the results indicate that it was the semi-polar compounds that have activity on blood pressure, so to ensure the specific compounds that play a role in blood pressure further study is needed. At present, it is suspected that luteolin has activity on blood vessels produced by $S$. arvensis

\section{CONCLUSION}

The antihypertension effect of the Sonchus arvensis is useful for developing traditional medicine for reducing the prevalence of hypertension. The semi-polar compound on S. arvensis has the potential in controlling the blood pressure. The candidate compound which has correlated to the effect is flavonoid groups. The candidate of the semi-polar compound from Sonchus arvensis is luteolin. It is a compound that has a good pharmacology effect of regulating blood pressure, but it was needed to determine the specifics of active compounds in further research to carry out the process of isolating the compounds followed by screening for activity tests 
RASĀYAN J. Chem.

Vol. 13 | No. 3 |1807-1816| July - September | 2020

\section{ACKNOWLEDGEMENT}

This study is part of doctoral program research. We thank the Directorate General of Higher Education of Education Ministry of Republik Indonesia for its financial support. The name of the grant is Pendidikan Magister Sarjana Doktor Unggulan Batch II-2015, grant number 134/SP2H/LT/DRPM/IV/2017 and also thank Department of Pharmacology, Faculty of Pharmacy, University of Jenderal Achmad Yani, Cimahi, Indonesia, which allowed us to work and assisted us in using KENT Scientific CODA's System instrument at the Laboratory of Pharmacology.

\section{REFERENCES}

1. World Health Organization, World Health Statistics 2012 Indicator Compendium, WHO Press, France, p109(2012).

2. R.N. Haldar, Indian Journal of Physical Medicine and Rehabilitation, 24, 1(2013), DOI: $10.5005 /$ ijopmr-24-1-2

3. Health Reasearch and Development of Ministry of Health Republic of Indonesia. Hasil Utama Riskesdas 2018, Ministry of Health Republic of Indonesia, Jakarta, p82-84(2018).

4. Health Reasearch and Development of Ministry of Health Republic of Indonesia. Riset Kesehatan Dasar 2013, Ministry of Health Republic of Indonesia, Jakarta, p5, 123-126(2013).

5. A.E. Sukmayadi, S.A. Sumuwi, M. Intan B, A.D. Aryanti. Indonesian Journal of Pharmaceutical Science and Technology, 1, 2(2014), DOI:10.15416/ijpst.v1i2.7515

6. Y.J. Xu, S.B. Sun, L.M. Sun, D.F. Qiu, X.J. Liu, Z.B. Jiang, C.S. Yuan, Food Chemistry, 111, 1 (2008), DOI: $10.1016 /$ j.foodchem.2008.03.028

7. R.A. Khan, M.R. Khan, S. Sahreen, J. Bokhari, African Journal of Biotechnology, 9, 25(2010)

8. R.A. Khan, Chemistry Central Journal, 6, 126(2012), DOI:10.1186/1752-153X-6-126

9. S.J. Prasad, P.B. Kumar, S.S. Raj, A. Sadhana, S.T. Maiya, A.M. Prasad, International Journal of Pharmacognosy and Phytochemical Research, 7, 3(2015)

10. H.M. Alkreathy, R.A. Khan, M.R. Khan, S. Sahreen, BMC complementary and alternative medicine, 14, 452(2014), DOI: 10.1186/1472-6882-14-452

11. L.B. Lumbanraja. Bachelor Final Project, Department of Pharmacology, University of Sumatera Utara, Medan, North Sumatera, Indonesia (2009).

12. R. Hendriani, E.Y. Sukandar, K. Anngadiredja, Sukrasno, International Journal of Pharmacy and Pharmaceutical Sciences, 6, 2(2014).

13. Y. Nurianti, R. Hendriani, E.Y. Sukandar, K. Anggadiredja, International Journal of Pharmacy and Pharmaceutical Sciences 6, 5(2014).

14. E.Y. Sukandar, A. N. Garmana, A.U. Aidasari, A. A. Crystalia, Journal of Research in Pharmacy, 23, 6(2019), DOI: $10.35333 /$ jrp.2019.73

15. Suryani, E.Y. Sukandar, A.B. Sutjiatmo, S.N. Vikasari. ICBBS '17: Proceedings of the 6th International Conference on Bioinformatics and Biomedical Science, Seoul, South Korea, pp. 124-128 (2017), DOI: $10.1145 / 3121138.3121195$

16. D.H.S. Palupi, D.S. Retroningrum, M.I. Iwo, A.A. Soemardji. Rasayan Journal of Chemistry, 13, 1(2020), DOI: 10.31788/RJC.2020.1315519

17. V. Alexandru, M. Balan, A. Gaspar, V. Coroiu, Planta Medica, 73, 6(2007), DOI:10.1055/s-2007987042

18. S. Chandra, S. Khan, B. Avula, H. Lala, M.H. Yang, M.A. ElSohly, I.A. Khan, Evidence-Based Complementary and Alternative Medicine, Volume 2014, (2014), DOI:10.1155/2014/253875

19. M. Mutakin, T. Juwita, S. Megantar, I.M. Puspitasari, J. Levita, Rasayan Journal of Chemistry, 13, 1379(2020), DOI: 10.31788/RJC.2020.1335723

20. E.Y. Sukandar, A. Ridwan, Y.P. Sukmawan, International Journal of Pharmacy and Pharmaceutical Sciences, 8, 2(2016)

21. Z. Jiang, C. Kempinski, J. Chappell, Current Protocols in Plant Biology, 1, 2(2016), DOI: $10.1002 / \mathrm{cppb} .20024$

22. D. Dhawan, F. Gupta, International Journal of Biological Chemistry, 11, 1(2017), DOI: $10.3923 / \mathrm{ijbc} .2017 .17 .22$

23. M.A. Zaafan, H.F. Zaki, A.I. El-Brairy, S.A. Kenawy. Bulletin of Faculty of Pharmacy, Cairo 1815 
RASĀYAN J. Chem.

Vol. 13 | No. 3 |1807-1816| July - September | 2020

University 51, 1(2013), DOI:10.1016/j.bfopcu.2013.03.001

24. A. Bhaskar, A. Vinod, American Journal of Physiology - Advances in Physiology Education, 30, 3(2006), DOI: 10.1152/advan.00008.2006

25. J.S. Floras, P.E. Aylward, R.G. Victor, A.L. Mark, F.M. Abboud, The Journal of Clinical Investigation, 81, 4(1988), DOI: 10.1172/JCI113444

26. H. Majewski, L.H. Tung, M.J. Rand, Journal of Cardiovascular Pharmacology, 3, 1(1981), DOI: 10.1097/00005344-198101000-00016

27. F. Fontana, P. Bernardi, C. Pizzi, R.D. Toro, S. Sapmpinato, Central European Journal of Medicine, 3, (2008), DOI: 10.2478/s11536-007-0071-X

28. O. Frankl, Hypertension, 20, 4(1992), DOI:10.1161/01.hyp.20.4.583

29. M.G. Myers, J. De Champlain, Hypertension, 5, (1983), DOI:10.1161/01.HYP.5.4.591

30. J. Wu, M.H. Ji, Z.Y. Wang, W. Zhu, J.J. Yang, Y.G. Peng, Journal of Cardiovascular Pharmacology, 62, 3(2013), DOI:10.1097/FJC.0b013e3182a1e118

31. M. Morad, C. Sanders, J. Weiss. The Journal of Physiology, 311, 1(1981), DOI: 10.1113/jphysiol.1981.sp013606

32. J. Su, H.T. Xu, J.J. Yu, J/L. Gao, J. Lei, Q.S. Yin, B. Li, M.X. Pang, M.X. Su, W.J. Mi, S.H. Chen, G.Y. Lv, Evidence-Based Complementary and Alternative Medicine, Volume 2015, (2015), DOI: $10.1155 / 2015 / 364876$

33. M. L. Lázaro, Medicinal Chemistry, 9, 1(2009), DOI:10.2174/138955709787001712

34. M.L.L. Martins, H.P. Pacheco, I.G. Perini, D. Lenz, T.U.D. Andrade, D.C. Endringer. Brazilian Journal of Pharmaceutical Sciences, 49, 83(2013), DOI:10.1590/S1984-82502013000400020

35. J.L. Clark, P. Zahradka, C.G. Taylor, Nutrition Reviews, October, (2015), DOI:10.1093/nutrit/nuv048

[RJC-5843/2020] 